\title{
Enhancing the Performance of a Wind-Driven Grid- Connected Induction Generator
}

\author{
M.A. Abdel-halim and A.F. Almarshoud \\ College of Engineering, Qassim University, Buraidah, Saudi Arabia; \\ masamie@qec.edu.sa,dr_almarshoud@qec.edu.sa
}

\begin{abstract}
Objectives: optimizing the performance of wind-driven grid-connected cage induction generators for constant torque, constant mechanical power and constant wind speed conditions. The optimization aimed to maximize the power factor, minimize the total losses, minimize the input reactive power, minimize the output current or maximize the efficiency. Methodology: Closed form formulas for the optimizing slips based on a circuit model having linear parameters have been derived for constant driving torque and constant input mechanical power conditions. Optimizing slips have been derived for many performance indices. Also, computer-implemented algorithms, which scan the performance characteristics of the generator, and determine the optimizing slips, have been developed for the constant torque, constant mechanical power and constant wind-speed conditions. With the aid of these algorithms, the electromagnetic saturation effects have been considered. Closed loop system utilizing micro-controller has been suggested for automatic optimization of the induction generator. Experimental tests have been carried out on a laboratory setup, and the computed results have been compared with the measured ones. Findings: The computed results when compared to the experimental measurements confirm the feasibility of the presented optimization theoretical techniques and the derived formulas. The experimental work assured that the proposed optimization technique is easy to be achieved through simply variation of the applied terminal voltage. Application/Improvements: The presented technique has improved the performance of the induction generator. Thus, it could be used to enhance the performance of small and moderate size wind-driven grid-connected constant speed cage induction generator system. The suggested control technique will enrich utilization of wind energy.
\end{abstract}

Keywords: Induction Generator, Performance Optimization, Wind Energy

List of Symbols:

$\mathrm{E}_{1}$ : stator induced voltage

$\mathrm{I}_{1} \quad$ : stator current

$\mathrm{I}_{2}$ : rotor current

$I_{e}:$ excitation current

$\mathrm{P}_{\mathrm{m}}$ : input mechanical power

$\mathrm{R}_{1}$ : stator resistance

$\mathrm{R}_{2}$ : rotor resistance

$\mathrm{R}_{c}$ : core resistance

$s$ : per unit slip

$\mathrm{T}_{\mathrm{m}}$ : input mechanical torque

$\mathrm{X}_{1}$ : stator leakage reactance

$\mathrm{X}_{2}$ : rotor leakage reactance

$\mathrm{X}_{\mathrm{m}}$ : magnetizing reactance

$\mathrm{V}_{1}$ : stator applied voltage

$W_{\mathrm{s}}:$ wind speed

\section{Introduction}

The utilization of wind energy has become vital as all the experts have expected great shortage of the conventional energy resources. Therefore, generation of electrical energy from the renewable wind energy is essential to face the expected energy crisis. In this regard, the winddriven grid-connected induction generator systems are commonly used. The grid-connected induction generators get its necessary reactive power from the network ${ }^{1-2}$. Control of these induction generators may be achieved via the use of solid-state converters in the stator and/or the rotor sides. Many authors optimized the performance of double-fed induction generators through voltage injection in the rotor circuit or frequency control of the stator voltage and adding resistance in the rotor circuit $\frac{3-10}{}$.

${ }^{*}$ Author for correspondence 
In constant speed cage induction generator, the need may arise to enhance the performance of the generator when the wind speed varies. This can be done through change of the generator terminal voltage. Change of the terminal voltage is achievable via the use of ac voltage controller inserted between the generator and the bus$\mathrm{bar}^{11}$. If the terminal voltage is varied, the generator speed will be adjusted to a certain value such that a chosen performance index is optimized.

Optimization of the performance of the induction motor, especially at light loads, has been investigated by previous authors ${ }^{12}$. The performance of the motor has been optimized for two loading conditions, namely; constant torque condition and constant output mechanical power condition. Performance optimization has been achieved through adjustment of the applied voltage.

In previous works $\frac{13}{13}$, the present authors determined the slips which optimize the performance of single-fed induction generators for constant driving torque condition through controlling the stator voltage. The constant driving torque condition is not applicable when the generator is driven by wind turbines. In the present paper, the performance of a grid-connected induction generator will be ameliorated for three different driving conditions, namely; constant driving torque, constant input mechanical power and constant wind speed. This ensures covering most of the possible driving conditions. The optimization techniques will be based on a steady-state circuit model. Closed form formulas for the optimizing slips, neglecting the magnetic saturation effects, will be derived for both the constant torque and constant input mechanical power conditions. Also, computer-implemented algorithms which scan the performance characteristics of the generator over a wide range of generator speeds including the desired optimum point have been developed. These algorithms cover the constant torque, constant mechanical power and constant wind-speed driving conditions. The algorithms enable taking into consideration the electromagnetic nonlinearities effects upon the generator parameters. Each slip optimizes one of the generator variables. This may be either minimizing the output current, maximizing the output power, minimizing the total losses, minimizing the input reactive power, maximizing the generator efficiency, or maximizing the power factor. A closed loop automatic control system will be suggested to optimize the induction generator performance. The system will utilize a micro-controller to control the duty cycle of the $\mathrm{AC}$ voltage controller to adjust the voltage applied on the generator such that the generator runs at the optimizing slip value.
Experimental measures have been carried out on an open loop laboratory setup, and the computed results have been compared with the measured results for all the three driving conditions. The comparison confirmed the validity of the generator optimization concept and the associated theoretical assumptions.

\section{Studied System}

The studied system consists of a cage induction generator connected to the network through an AC voltage controller, and driven by a wind turbine (Figure 1).

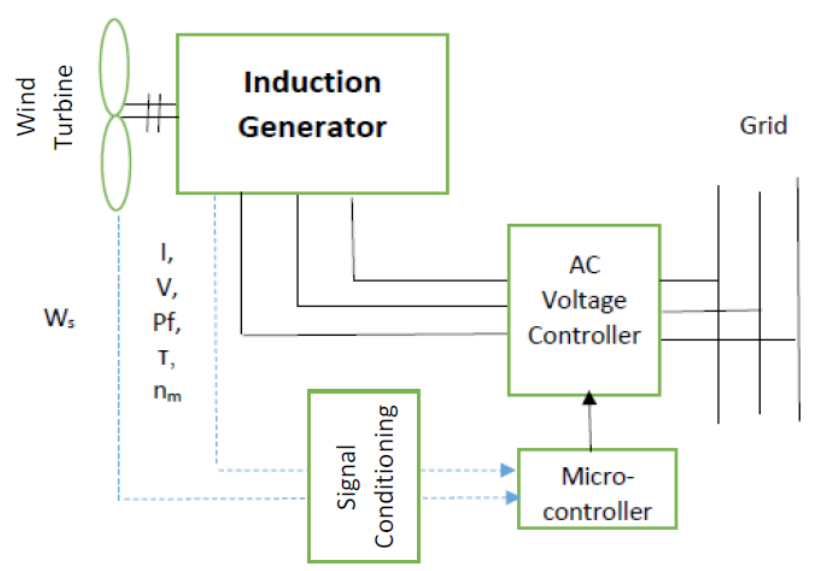

Figure 1. Studied system.

The AC voltage controller is designed to act as AC chopper. The value of the output voltage is controlled through variation of the duty cycle $e^{11}$ which is controlled via a micro-controller ${ }^{14}$.

\section{Induction Generator Modelling}

\subsection{Circuit Model}

Figure 2 shows the frequency domain per-phase circuit model of the 3-phase induction generator ${ }^{15}$.

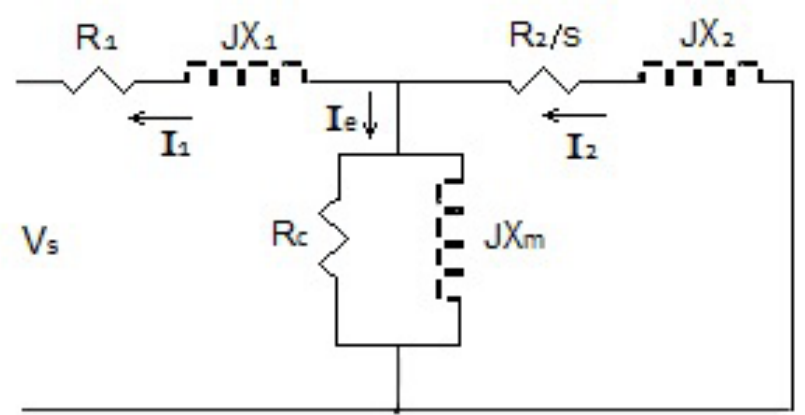

Figure 2. Per-phase equivalent circuit of the induction generator. 


\subsection{Mathematical Model}

Using the well-known relation between the air gap power and the torque $e^{6}, I_{2}$, in p.u, is determined in terms of the input torque or the input mechanical power as follows:

$$
\begin{aligned}
& \mathrm{P}_{\mathrm{m}}=\mathrm{I}_{2}{ }^{2} \mathrm{R}_{2}(1-\mathrm{s}) / \mathrm{s} \\
& \mathrm{T}_{\mathrm{m}}=\mathrm{P}_{\mathrm{m}} /(1-\mathrm{s})=\mathrm{I}_{2}{ }^{2} \mathrm{R}_{2} / \mathrm{s}
\end{aligned}
$$

Then, $\mathrm{I}_{2}$, in terms of $\mathrm{T}_{\mathrm{m}}$ or $\mathrm{P}_{\mathrm{m}}$ is given by:

$$
\begin{aligned}
& \mathrm{I}_{2}=\left[\mathrm{T}_{\mathrm{m}} \mathrm{S} / \mathrm{R}_{2}\right]^{1 / 2} \\
& \mathrm{I}_{2}=\sqrt{\frac{P_{m} S}{(1-s) R_{2}}}
\end{aligned}
$$

Based on the equivalent circuit of induction generator in Figure 1, the equations which relate the generator output voltage and current to the generator slip and parameters are as follows:

$$
\begin{aligned}
& \mathbf{E}_{1}=-\mathbf{I}_{2}\left(R_{2} / \mathrm{s}+\mathrm{j} X_{2}\right) \\
& \mathbf{I}_{\mathrm{e}}=\mathbf{E}_{1}\left(1 / \mathrm{R}_{\mathrm{c}}-\mathrm{j} 1 / \mathrm{X}_{\mathrm{m}}\right)
\end{aligned}
$$

$$
\begin{aligned}
& \mathbf{I}_{1}=\mathbf{I}_{2}-\mathbf{I}_{\mathrm{e}} \\
& \mathbf{V}_{1}=\mathbf{E}_{1}-\mathbf{I}_{1}\left(\mathbf{R}_{1}+\mathbf{j} \mathbf{X}_{1}\right)
\end{aligned}
$$

\section{Optimum Slips Closed Form Formulas}

Equations 3-8 may be used to derive closed form formulas for the optimum slips assuming linear equivalent circuit parameters. Formulae for the performance indices, namely; output current $\left(\mathrm{I}_{1}\right)$, total losses $\left(\mathrm{P}_{\mathrm{L}}\right)$, Input reactive power $(\mathrm{Q})$, output electrical power $\left(\mathrm{P}_{\mathrm{e}}\right)$, efficiency $(\eta)$ and power factor $(\mathrm{Pf})$ are derived for constant driving torque and constant input mechanical power conditions (Appendix A). Then, the generator optimizing slips are derived as functions of the generator equivalent circuit parameters. Proper approximations are applied to simplify the obtained formulae. The optimizing slips' formulae are given in Tables 1 and 2.

Table 1. Optimizing slips in per-unit for constant driving torque

\begin{tabular}{|l|l|l|l|}
\hline $\begin{array}{l}\text { Minimum output } \\
\text { current }\end{array}$ & $=-\frac{\text { Maximum }}{(X \quad X)}$ & $\begin{array}{l}\text { output power } \\
S_{e} \cong-\frac{R_{2}}{\sqrt{R_{1} R_{c}}}\end{array}$ \\
\hline Minimum losses & $S_{L} \cong-\frac{R_{2}}{\left[R_{c}\left(R_{1}+R_{2}\right)\right]^{1 / 2}}$ & $\begin{array}{l}\text { Minimum } \\
\text { input reactive } \\
\text { power }\end{array}$ & $S_{Q} \cong-\frac{R_{2}}{\left[X_{M}\left(X_{1}+X_{2}\right)\right]^{1 / 2}}$ \\
\hline $\begin{array}{l}\text { Maximum } \\
\text { efficiency }\end{array}$ & $S_{\eta}=-\frac{R_{2}}{\left[R_{c}\left(R_{1}+R_{2}\right)\right]^{1 / 2}}$ & $\begin{array}{l}\text { Maximum } \\
\text { power factor }\end{array}$ & $S_{p f}=\frac{-X_{2} R_{2} X_{M}-\sqrt{4\left(X R_{2} X_{M}-R_{1} R_{2} R_{c}\right)^{2}+4 X R_{2}^{2} X_{M} R_{c}^{2}}}{2 X X_{M} R_{C}}$ \\
Where: $\mathrm{x}=\mathrm{x} 1+\mathrm{x} 2$
\end{tabular}

Table 2. Optimizing slips in per-unit for constant input mechanical power

\begin{tabular}{|l|l|l|l|}
\hline $\begin{array}{l}\text { Minimum output } \\
\text { current }\end{array}$ & $S_{I}^{\prime} \cong-\frac{R_{2}}{X_{M}^{1 / 2}\left(X_{M}+2 X_{2}\right)^{1 / 2}}$ & $\begin{array}{l}\text { Maximum } \\
\text { output power }\end{array}$ & \begin{tabular}{l}
$S_{e}^{\prime} \cong-\frac{R_{2}}{\left[R_{c}\left(R_{1}+R_{2}\right)\right]^{1 / 2}}$ \\
\hline Minimum losses
\end{tabular} \\
$S_{L}^{\prime} \cong-\frac{R_{2}}{\left[R_{c}\left(R_{1}+R_{2}\right)\right]^{1 / 2}}$ & $\begin{array}{l}\text { Minimum } \\
\text { input reactive } \\
\text { power }\end{array}$ & $S_{Q}^{\prime} \cong-\frac{R_{2}}{\left[X_{M}\left(X_{1}+X_{2}\right)\right]^{1 / 2}}$ \\
\hline $\begin{array}{l}\text { Maximum } \\
\text { efficiency }\end{array}$ & $S_{\eta}^{\prime} \cong-\frac{R_{2}}{\left[R_{c}\left(R_{1}+R_{2}\right)\right]^{1 / 2}}$ & $\begin{array}{l}\text { Maximum } \\
\text { power factor }\end{array}$ & $\begin{array}{l}S_{p f}^{\prime}=\frac{-X_{2} R_{2} X_{M}-\sqrt{4\left(X R_{2} X_{M}-R_{1} R_{2} R_{c}\right)^{2}+4 X R_{2}^{2} X_{M} R_{c}^{2}}}{2 X X_{M} R_{C}} \\
\text { Where: } x=x_{1}+x_{2}\end{array}$ \\
\hline
\end{tabular}


It can be noted from the previous formulae that the optimizing slips are independent of the values of the driving torque or the driving power as long as electromagnetic nonlinearities are neglected.

\section{Algorithms for Accurate Computation of the Optimizing Slips}

To check the derived closed form formulae of the optimizing slips, and to enable considering the electromagnetic nonlinearities of the generator parameters, algorithms have been designed to determine these slips using a computer developed program. Due to electromagnetic saturation $R_{c}$ and $\mathrm{X}_{\mathrm{m}}$ will not be constant, they will depend onhe air gap flux, and consequently on the internal induced voltage $\left(\mathrm{E}_{1}\right) \frac{15}{}$.

\subsection{Constant Input Torque Algorithm}

Based on the generator equivalent circuit shown in Figure 1 , and assuming that the driving torque is constant at a value $\left(T_{m}\right)$, then at an assumed slip $(s)$,

1. The rotor referred current is calculated using Eq. 3 .

2. The rotor referred voltage phasor; $\mathbf{E}_{1}$, is calculated using Eq. 5

3. The values of both $X_{m}$ and $R_{c}$ are determined corresponding to the magnitude of $\mathbf{E}_{1}$. The relations between both $\mathrm{X}_{\mathrm{m}}$ and $\mathrm{R}_{\mathrm{c}}$ and $\mathrm{E}_{1}$ are governed by the electro-magnetic saturation phenomenon in the machine, or they are fixed to the unsaturated value if saturation is neglected.

4. The excitation current; $\mathbf{I}_{\mathrm{e}^{\prime}}$ is then calculated using Eq. 6.

5. The stator current; $\mathrm{I}_{1}$, is then calculated, using Eq. 7 .

6. The required terminal voltage; $\mathrm{V}_{1}$, is then calculated using Eq. 8.

7. The input, output, efficiency, losses, power factor and reactive power are, then, calculated using the conventional relations.

If the slip is varied in a range and the generator different quantities are calculated, there will be a slip value which optimizes one of the generator performance indices. This slip is obtained at a certain generator terminal voltage.

\subsection{Constant Input Mechanical Power Algorithm}

In this case, the input mechanical power to the generator; $\mathrm{P}_{\mathrm{m}}$, is assumed constant. Then, at an assumed slip (s),

1. The rotor referred current is calculated using Eq. 4.

2. The optimization algorithm used for the constant torque case is then followed starting from step (2).

\subsection{Constant Wind Speed Algorithm}

The input mechanical power and torque to the generator are determined from the wind turbine characteristic at this wind speed and the turbine speed as follows ${ }^{16-18}$ :

$$
\begin{aligned}
& \mathrm{P}_{\mathrm{m}}=0.5 \rho \pi R_{\mathrm{b}}{ }^{2} \mathrm{C}_{\mathrm{p}}(\lambda, \beta) W_{\mathrm{s}}^{3} \\
& \mathrm{~T}_{\mathrm{m}}=0.5 \rho \pi R_{\mathrm{b}}{ }^{3} \mathrm{C}_{\mathrm{Q}}(\lambda, \beta) W_{\mathrm{s}}^{2}
\end{aligned}
$$

Where $\mathrm{C}_{\mathrm{P}}$ and $\mathrm{C}_{\mathrm{Q}}$ are the power and torque coefficients, respectively. These are functions of the pitch angle; $\beta$, and the so-called tip-speed-ratio; $\lambda$, defined as:

$$
\lambda=\Omega_{\mathrm{r}} R_{\mathrm{b}} / W_{\mathrm{s}}
$$

Where $\Omega_{\mathrm{r}}$ is the turbine angular mechanical speed and $R_{\mathrm{b}}$ is its blade radius. Figure 3 shows typical variations of $C_{\mathrm{Q}}$ and $C_{\mathrm{p}}$ for a fixed-pitch wind turbine $\frac{17-19}{\text {. The algorithm of }}$ computation is as follows:

In this case, the wind speed; $W_{s}$, is assumed constant. Then at an assumed slip (s)

1. $\lambda$ is calculated, then $C_{Q}$ is obtained from the turbine characteristics.

2. The wind driving torque is calculated.

3. The rotor referred current is calculated using Eq. 3.

4. The optimization algorithm used for the constant torque case is then followed starting from step (2).

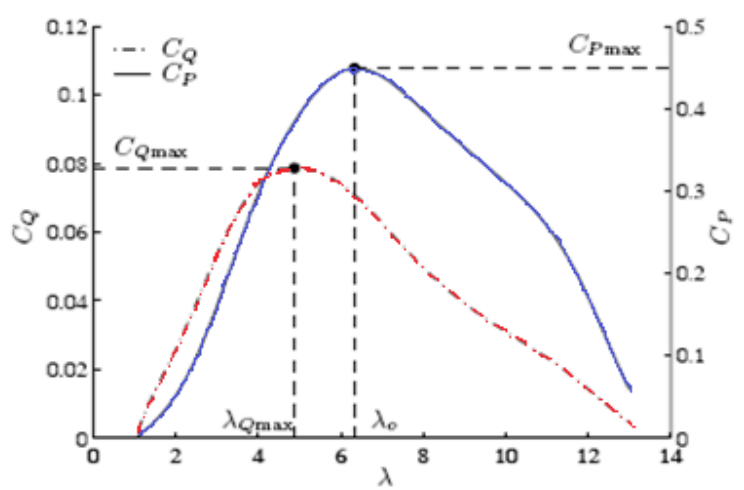

Figure 3. Typical variations of $\mathrm{C}_{\mathrm{Q}}$ and $\mathrm{C}_{\mathrm{P}}$ for a fixedpitch wind turbine. 
In all previous driving conditions, the optimized performance will be feasible if the voltage giving the optimum slip satisfies the condition $\mathrm{V}_{\mathrm{s}} \leq \mathrm{V}_{\text {rated }}$ and the current satisfies the condition $\mathrm{I}_{1} \leq \mathrm{I}_{\text {rated }}$

\section{Closed Loop Control}

A feedback closed loop control system utilizing a microcontroller is suggested for automatic control of the generator such that it operates at the required slip. The controller receives 6 signals, namely; the wind-speed, rms voltage, rms current, power factor, generator input torque, and shaft speed (Figure 3). Using these signals, the microcontroller calculates at the sensed wind-speed the input mechanical power, output electrical power, total losses, efficiency and input reactive power. Two techniques are suggested to control the generator such that it runs at the optimizing slip. These are search control technique and lookup table technique.

\subsection{Search Control Technique}

This technique is based on keeping varying the duty cycle of the AC voltage controller till the optimum point as regarding one of the variables is reached. This requires continuous comparison of the operating point with the previously stored point utilizing the microcontroller.

The pattern of variation of the optimized variables has one optimum point with no local optimum points. This guarantees the success of this technique. The generator voltage and current values should be observed during the variation process to avoid violating the constraints. This technique is suitable when the parameters of the generator equivalent circuit are not known.

\subsection{Lookup Table Techniques}

At the sensed wind speed, the duty cycle of the AC voltage controller corresponding to the optimizing slip of the specified variable is picked from a stored lookup table in the micro-controller. This technique is suitable for generators with known equivalent circuit parameters. Micro-controller shown in Figure 4 gives signals to the driving circuit of the AC voltage controller to adjust the duty cycle at the specified value. This will drive the generator to the optimum point.

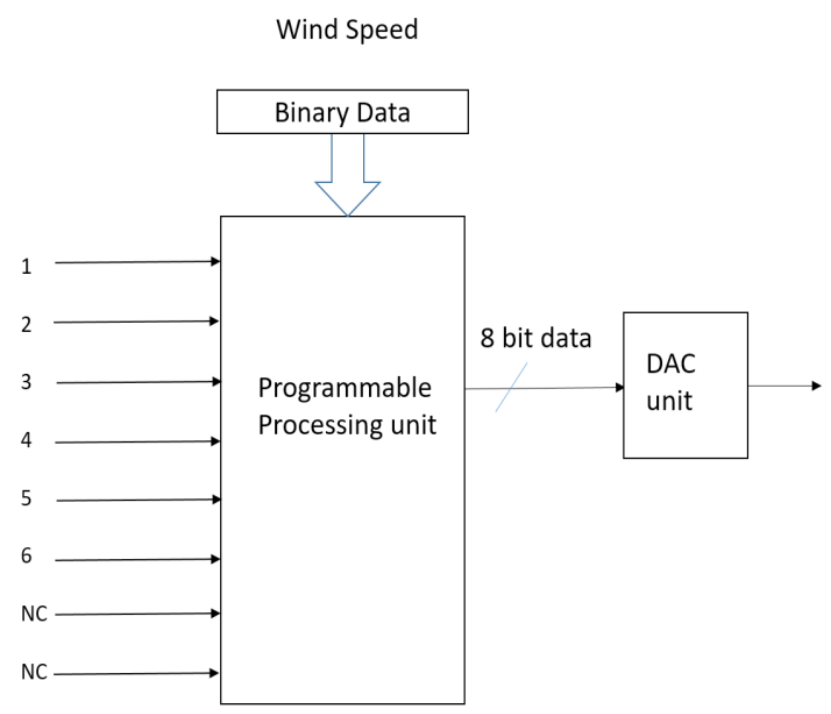

1: Max. Pf, 2: Min. losses, 3: Min. Reactive Power, 4: Min. current, 5: Max. Electrical Output, 6: Max. Efficiency

Figure 4. Block Diagram and details of the microcontroller.

The wind has a variable nature as regarding the speed and the direction. To avoid continuous transient operation of the generator, discretization technique is suggested. The wind speed ranges are divided into steps, and the induction generator is maintained working steadily at terminal voltage corresponding to the mean wind speed of the step as long as the wind-speed is within this step. Transition to another point is allowed once the wind speed jumps to another step. A reasonable delay is imposed on the action of the micro-controller to avoid changes due to pulse wind variation.

\section{Computed Results}

The machine having the parameters given in Appendix $B$ was used to calculate the optimum slip values using the closed form formulae when neglecting the saturation effects. Also, a computer program has been developed to calculate these slips using the algorithms given in Section 5. The computer program enabled calculation of the optimum slips when neglecting the saturation and considering it. The curves relating $\mathrm{R}_{\mathrm{c}}$ and $\mathrm{X}_{\mathrm{m}}$ to the induced voltage of the motor under study have been fitted to suit computer program calculations (Appendix B). 
The calculated optimizing slips using the closed form formulae (Table 3) showed full agreement with those computed by the computer program when saturation is neglected.

Table 3. Per-unit optimum slips neglecting saturation

\begin{tabular}{|c|c|c|c|c|c|c|}
\hline Optimized index & Output current & Power factor & $\begin{array}{l}\text { Generator } \\
\text { total losses }\end{array}$ & $\begin{array}{l}\text { Input reactive } \\
\text { power }\end{array}$ & $\begin{array}{l}\text { Output } \\
\text { electrical power }\end{array}$ & Efficiency \\
\hline $\begin{array}{l}\text { Optimizing slip at constant } \\
\text { driving torque }\end{array}$ & -0.029 & -0.102 & -0.03 & -0.100 & -0.039 & -0.030 \\
\hline $\begin{array}{l}\text { Optimizing slip at constant } \\
\text { driving mechanical power }\end{array}$ & -0.029 & -0.102 & -0.03 & -0.100 & -0.03 & -0.03 \\
\hline
\end{tabular}

Using the algorithms illustrated in Section 5, the generator performance characteristics when neglecting and considering the saturation have been computed at two different values of each of the driving torques, the input mechanical power and the wind speed. The characteristics are depicted in Figures (5-10).
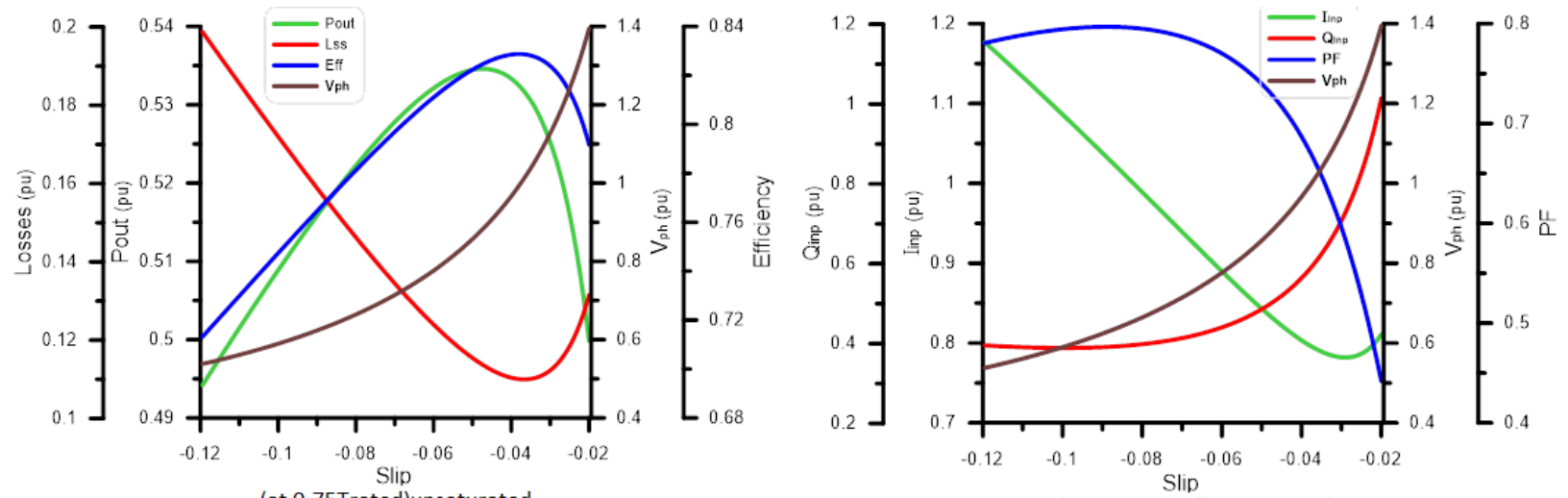

(at 0.75 Trated)unsaturated

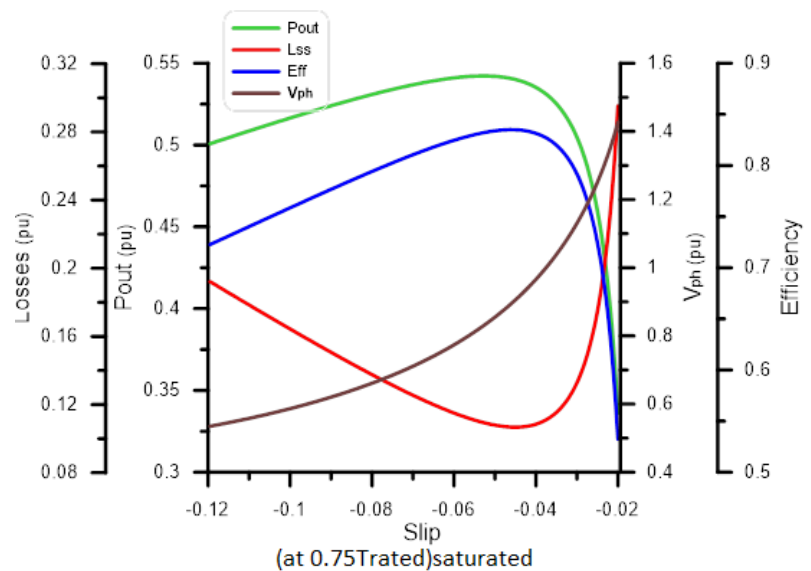

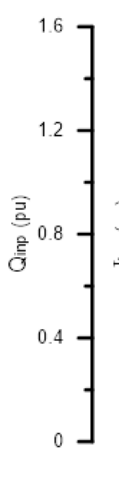

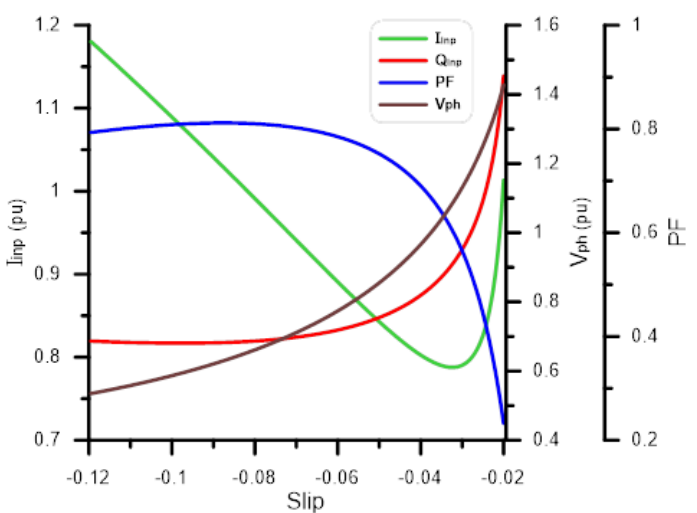

(at 0.75 Trated)saturated

Figure 5. Performance curves at constant driving torque at 0.75 times the rated torque. 

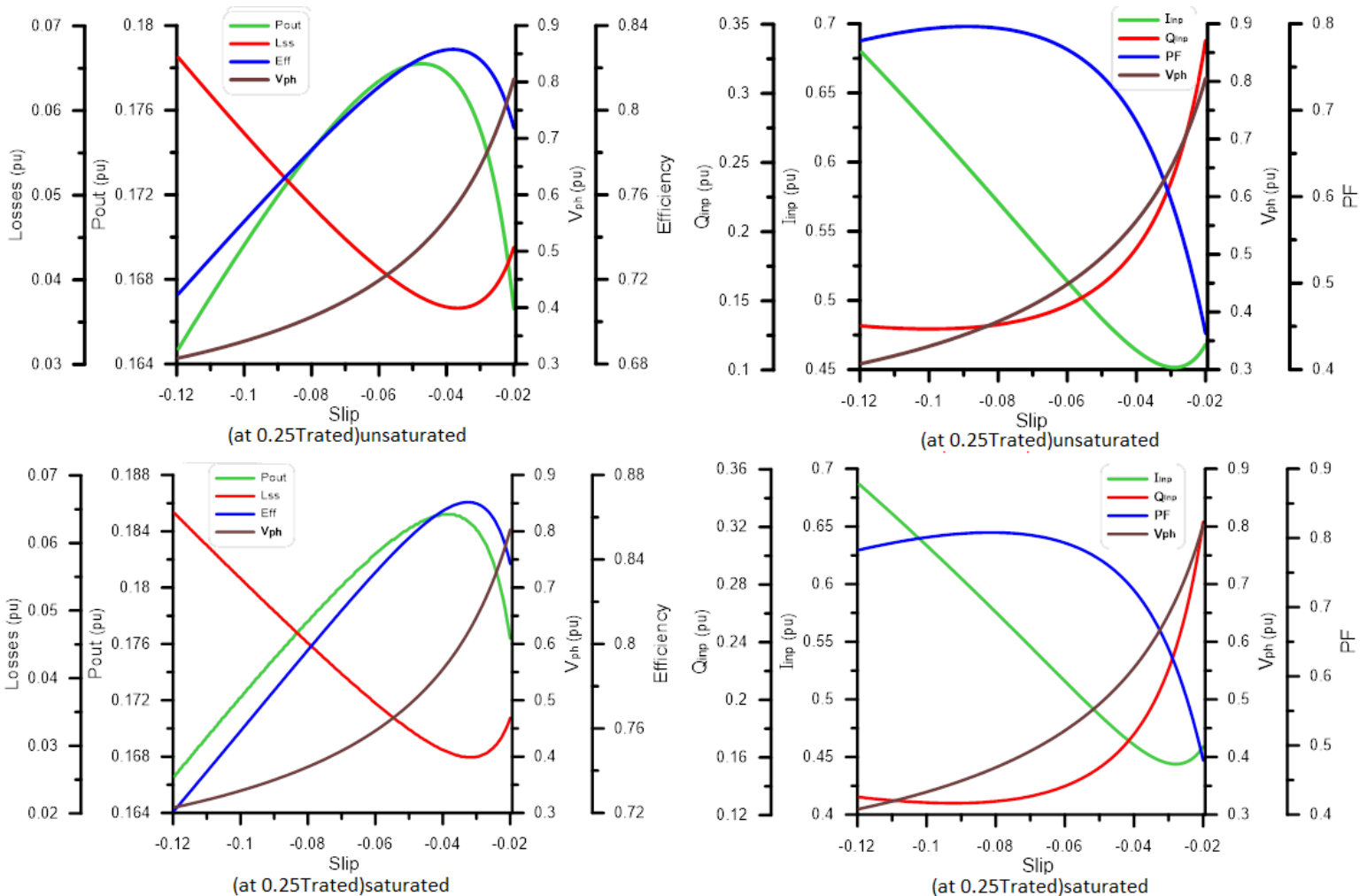

Figure 6. Performance curves at constant driving torque at 0.25 times the rated torque.

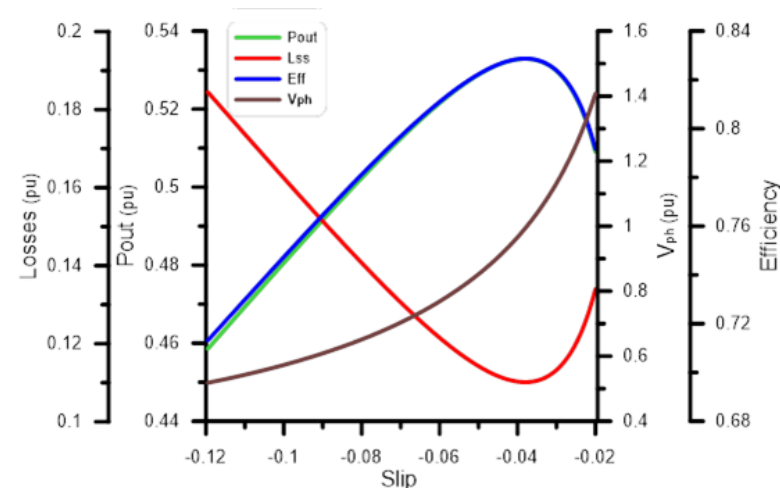

(at 0.75Prated)unsaturated
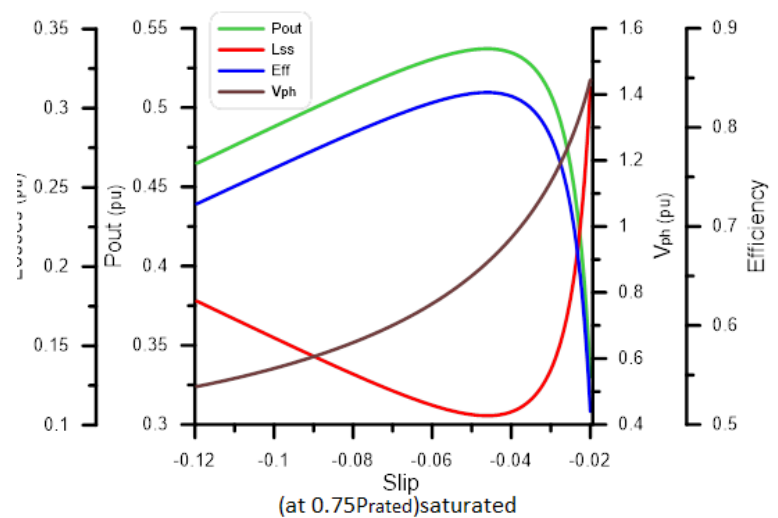
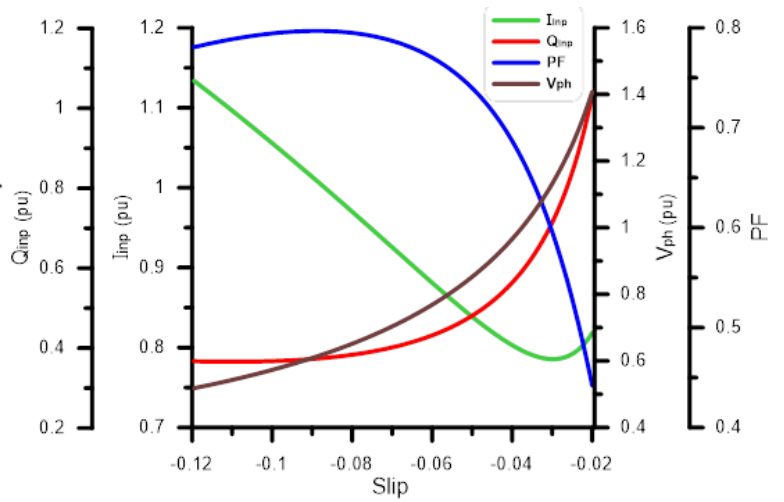

(at 0.75Prated)unsaturated

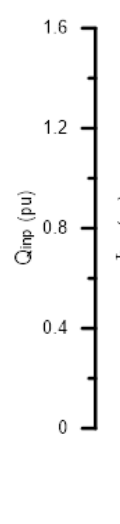

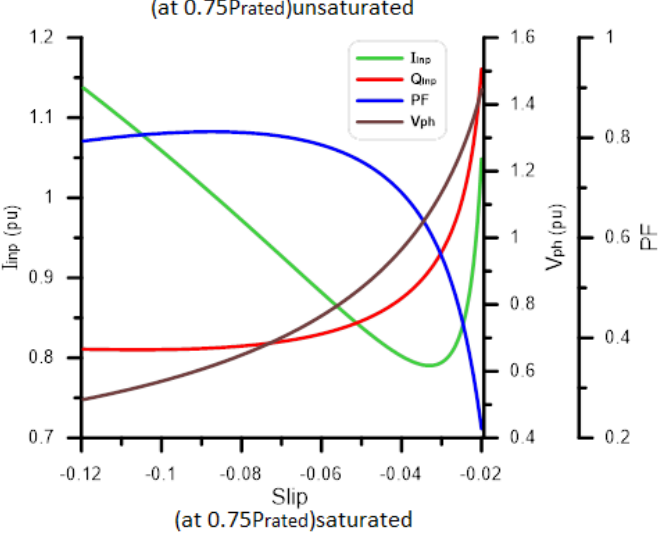

Figure 7. Performance curves at constant driving mechanical power at 0.75 times the rated input mechanical power. 

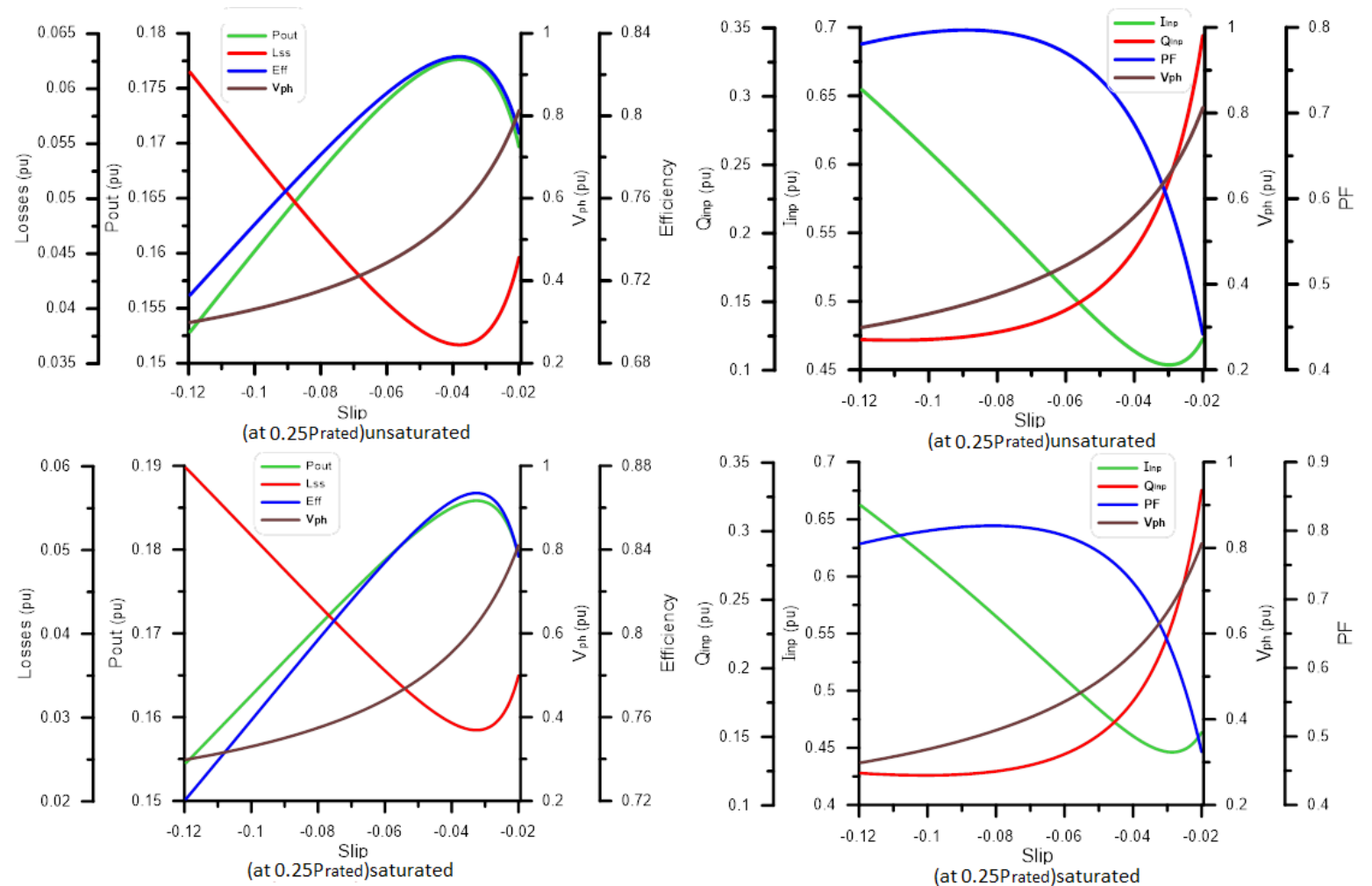

Figure 8. Performance curves at constant driving mechanical power at 0.25 times the rated input mechanical power.
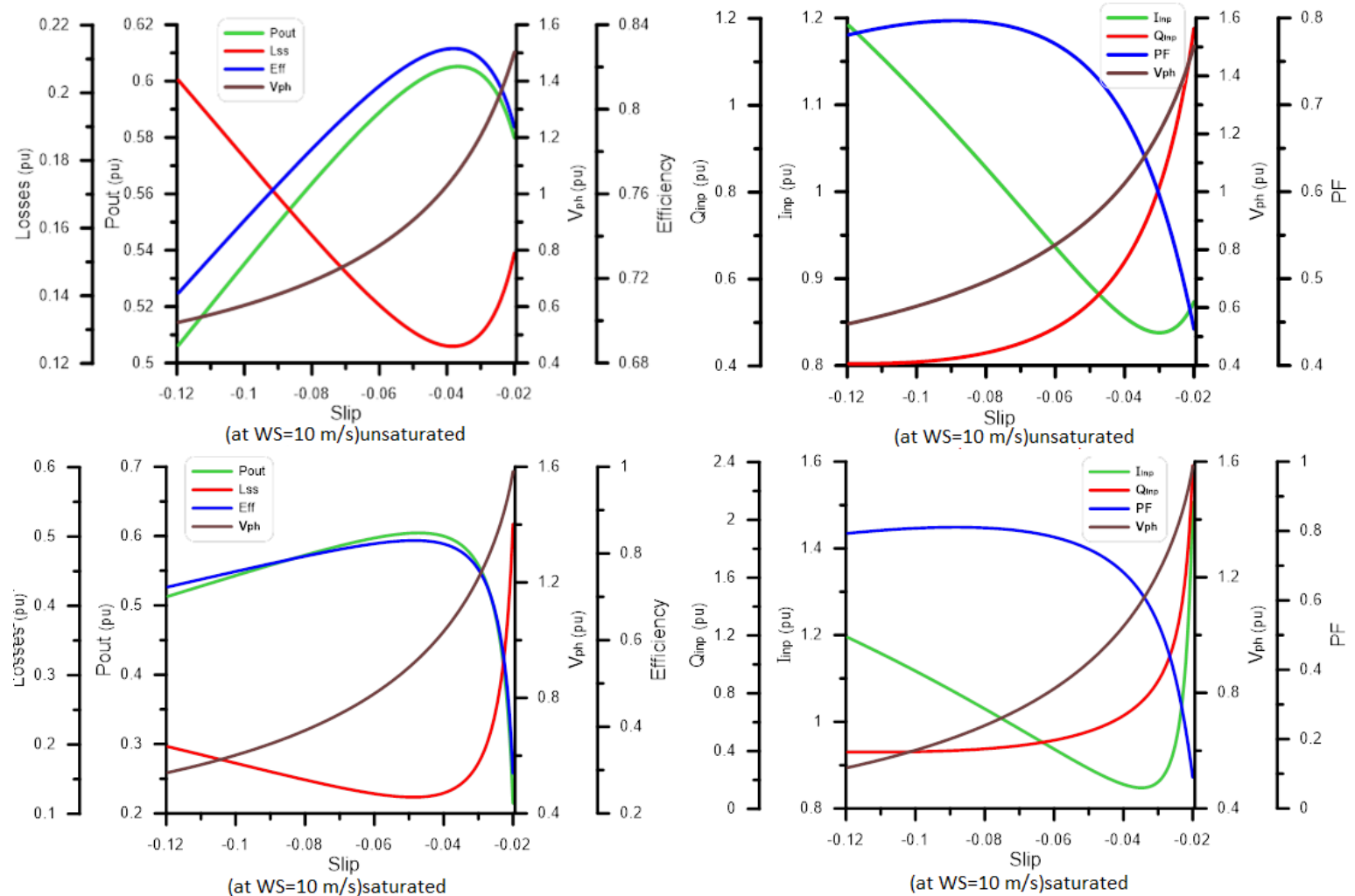

Figure 9. Performance curves at constant wind speed $(10 \mathrm{~m} / \mathrm{s})$. 

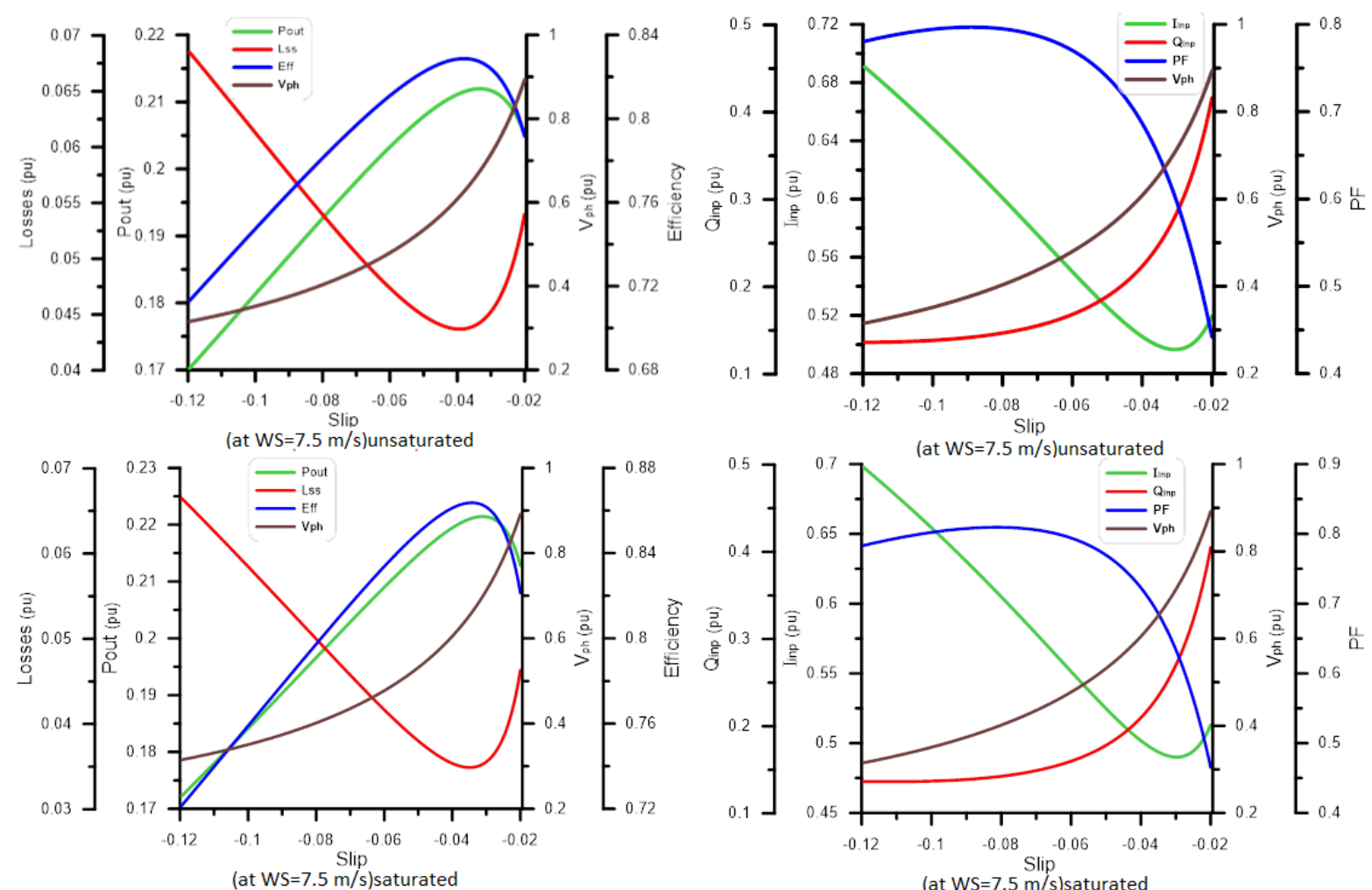

Figure 10. Performance curves at constant wind speed $(7.5 \mathrm{~m} / \mathrm{s})$.

The values of the optimum slips when saturation is considered are extracted from these characteristics. The optimizing slip values when saturation is considered are given in Tables 4-6 for constant driving torque, constant input mechanical power and constant wind speed, respectively.

Table 4. Per-unit optimizing slips for constant driving torque

\begin{tabular}{|l|c|c|c|c|c|c|}
\hline Optimized index & $\begin{array}{c}\text { Output } \\
\text { current }\end{array}$ & Power factor & Total losses & $\begin{array}{c}\text { Input reactive } \\
\text { power }\end{array}$ & $\begin{array}{c}\text { Output electrical } \\
\text { power }\end{array}$ & Efficiency \\
\hline Optimizing slip at 0.75 & $-0.034^{*}$ & $-0.090^{*}$ & $-0.046^{*}$ & $-0.092^{*}$ & $-0.052^{*}$ & $-0.046^{*}$ \\
rated torque & $-0.033^{* *}$ & $-0.067^{* *}$ & $-0.033^{* *}$ & $-0.079^{* *}$ & $-0.0335^{* *}$ & $-0.0325^{* *}$ \\
\hline Optimizing slip at 0.25 & $-0.028^{*}$ & $-0.082^{*}$ & $-0.032^{*}$ & $-0.09^{*}$ & $-0.048^{*}$ & $-0.030^{*}$ \\
rated driving torque & $-0.021^{* *}$ & $-0.066^{* *}$ & $-0.032^{* *}$ & $-0.071^{* *}$ & $-0.033^{* *}$ & $-0.032^{* *}$ \\
\hline
\end{tabular}

Table 5. Per-unit optimizing slips for constant driving power

\begin{tabular}{|c|c|c|c|c|c|c|}
\hline Optimized index & $\begin{array}{l}\text { Output } \\
\text { current }\end{array}$ & Power factor & Total losses & $\begin{array}{l}\text { Input reactive } \\
\text { power }\end{array}$ & $\begin{array}{c}\text { Output electrical } \\
\text { power }\end{array}$ & Efficiency \\
\hline $\begin{array}{l}\text { Optimizing slip at } 0.75 \\
\text { rated input mechanical } \\
\text { power }\end{array}$ & $\begin{array}{l}-0.034^{*} \\
-0.032^{* *}\end{array}$ & $\begin{array}{l}-0.090^{*} \\
-0.066^{* *}\end{array}$ & $\begin{array}{l}-0.048^{*} \\
-0.033^{* *}\end{array}$ & $\begin{array}{l}-0.11^{*} \\
-0.088^{* *}\end{array}$ & $\begin{array}{l}-0.048^{\star} \\
-0.033^{* *}\end{array}$ & $\begin{array}{l}-0.04^{*} \\
-0.033^{* *}\end{array}$ \\
\hline $\begin{array}{l}\text { Optimizing slip at } 0.25 \\
\text { rated input mechanical } \\
\text { power }\end{array}$ & $\begin{array}{l}-0.028^{*} \\
-0.022^{* *}\end{array}$ & $\begin{array}{l}-0.082^{*} \\
-0.065^{* *}\end{array}$ & $\begin{array}{l}-0.032^{*} \\
-0.031^{*}\end{array}$ & $\begin{array}{l}-0.101^{*} \\
-0.067^{* *}\end{array}$ & $\begin{array}{l}-0.032^{*} \\
-0.031^{*}\end{array}$ & $\begin{array}{l}-0.032^{*} \\
-0.031^{* *}\end{array}$ \\
\hline
\end{tabular}


Table 6. Per-unit optimizing slips for constant wind speed

\begin{tabular}{|c|c|c|c|c|c|c|}
\hline Optimized index & $\begin{array}{l}\text { Output } \\
\text { current }\end{array}$ & $\begin{array}{l}\text { Power } \\
\text { factor }\end{array}$ & Total losses & $\begin{array}{c}\text { Input reactive } \\
\text { power }\end{array}$ & $\begin{array}{l}\text { Output electri- } \\
\text { cal power }\end{array}$ & Efficiency \\
\hline $\begin{array}{l}\text { Optimizing slip at wind } \\
\text { speed of } 10 \mathrm{~m} / \mathrm{s}\end{array}$ & $\begin{array}{c}-0.035^{*} \\
--\end{array}$ & $\begin{array}{c}-0.088^{*} \\
--\end{array}$ & $\begin{array}{c}-0.0485^{\star} \\
--\end{array}$ & $\begin{array}{c}-0.113^{*} \\
-- \\
\end{array}$ & $\begin{array}{c}-0.0475^{*} \\
--\end{array}$ & $\begin{array}{c}-0.0485^{*} \\
--\end{array}$ \\
\hline $\begin{array}{l}\text { Optimizing slip at wind } \\
\text { speed of } 7.5 \mathrm{~m} / \mathrm{s}\end{array}$ & $\begin{array}{l}-0.0295^{*} \\
-0.028^{* *}\end{array}$ & $\begin{array}{l}-0.0815^{*} \\
-0.07^{* *}\end{array}$ & $\begin{array}{l}-0.035^{*} \\
-0.033^{* *}\end{array}$ & $\begin{array}{l}-0.1115^{*} \\
-0.089^{* *}\end{array}$ & $\begin{array}{l}-0.031^{*} \\
-0.028^{* *}\end{array}$ & $\begin{array}{l}-0.0345^{*} \\
-0.033^{* *}\end{array}$ \\
\hline
\end{tabular}

${ }^{*}$ Computed, ${ }^{* *}$ Measured

The tables show that the optimizing slips, considering the electromagnetic nonlinearities, depend on the generator operating condition. For constant driving torque the optimizing slips increase with the increase of the torque. Also, for constant driving mechanical power, the optimizing slips increase with the increase of the mechanical power. For constant wind speed, the optimizing slips increase with the increase of the wind speed.

\section{Experimental Verification}

To verify the validity of the optimization concept and the derived optimizing slips, experimental measurements have been carried out on the induction generator used for the theoretical computation.

\subsection{Experimental Setup}

The experimental setup consists of the induction generator, which is driven by a pendulum machine as a prime mover. The IG is connected to the ac supply through a variac. The connection circuit diagram and a photo of the experimental setup are shown in Figure 11. The output torque of the pendulum machine can be controlled independently of its speed. This will enable simulating the constant torque, constant driving power and constant driving wind speed conditions.

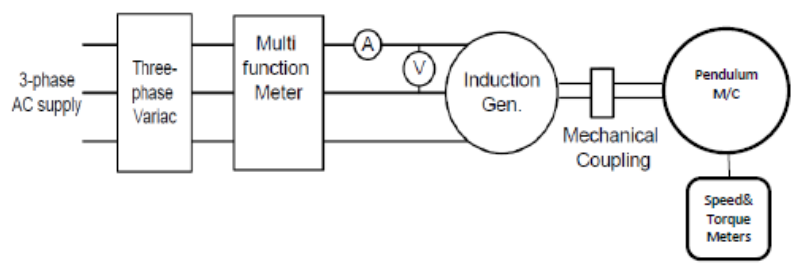

(a)

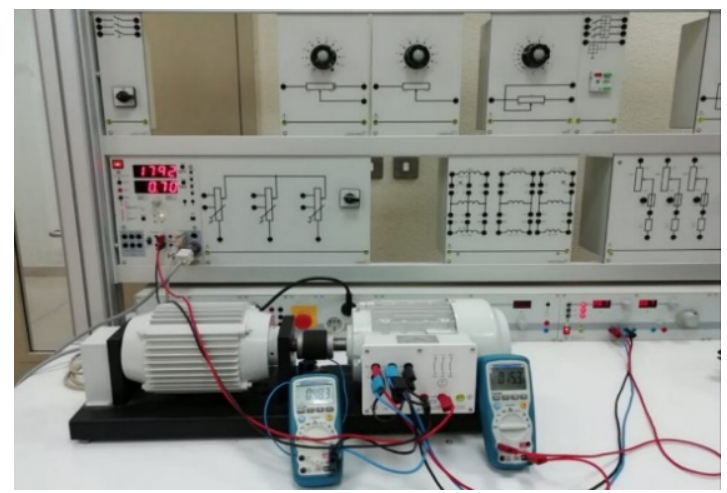

(b)

Figure 11. Experimental setup. a) Layout and connection diagram of the experimental setup; b) Photo picture of the experimental setup

\subsection{Experiment Procedures}

1. The induction machine is connected to the supply to start it as induction motor while the pendulum machine is not excited.

2. The driving pendulum machine is excited and the speed of the generator is varied by adjusting its terminal voltage using the variac.

3. The driving pendulum machine torque is adjusted to a value according to the required test conditions.

4. At different generator speeds all variables (voltage, current, output active power, input reactive power, power factor, etc) are recorded

The results for the three conditions, namely; constant driving torque, constant driving mechanical power and constant wind speed are depicted in Figures (12-17). The computed optimizing slips when saturation is considered are quite close to the values extracted from the experimental results (Tables 4-6). 

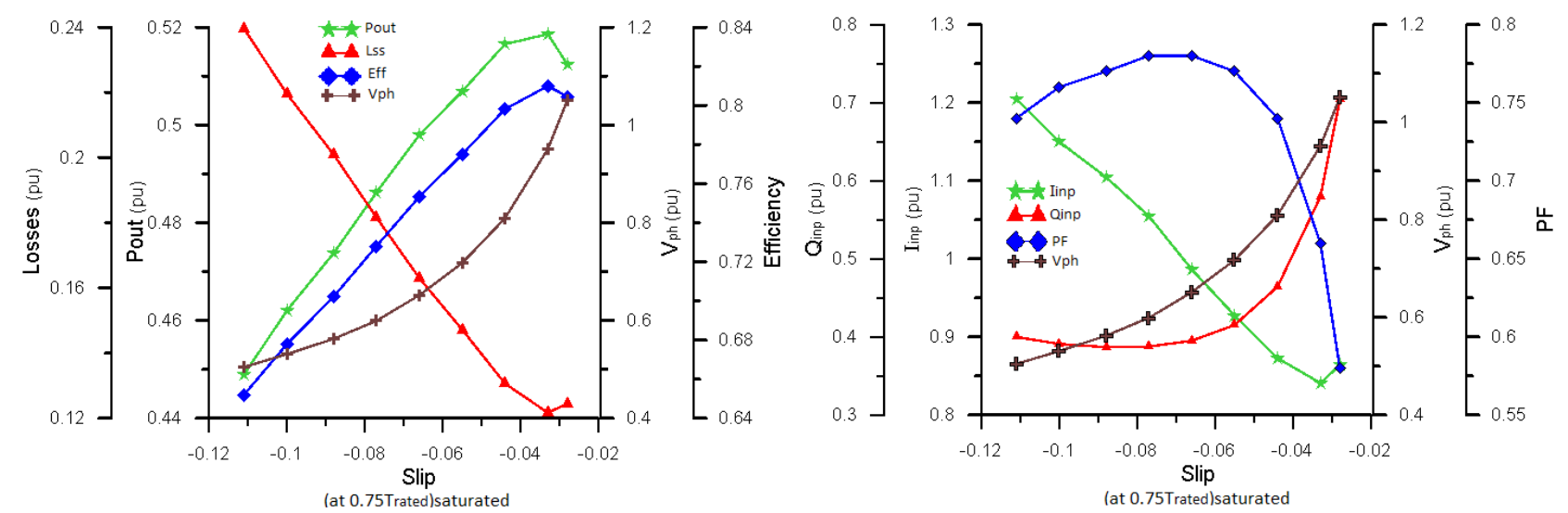

Figure 12. Experimental performance curves for constant driving torque ( 0.75 times the rated driving torque).
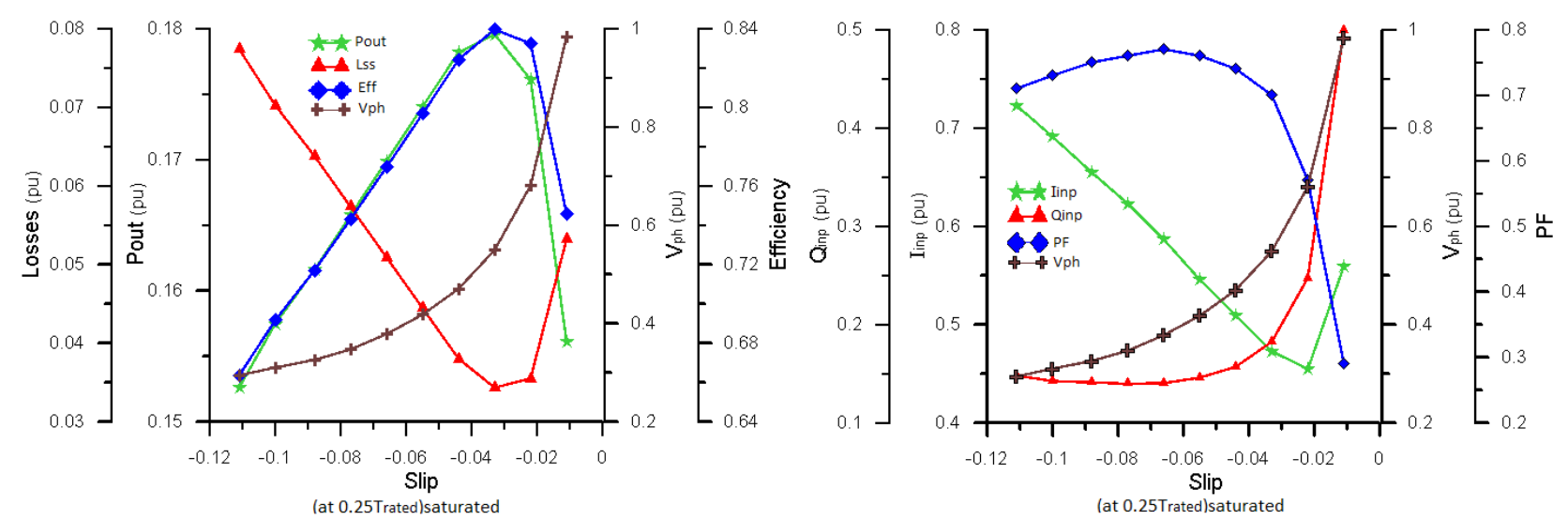

Figure 13. Experimental performance curves for constant driving torque ( 0.25 times the rated driving torque).
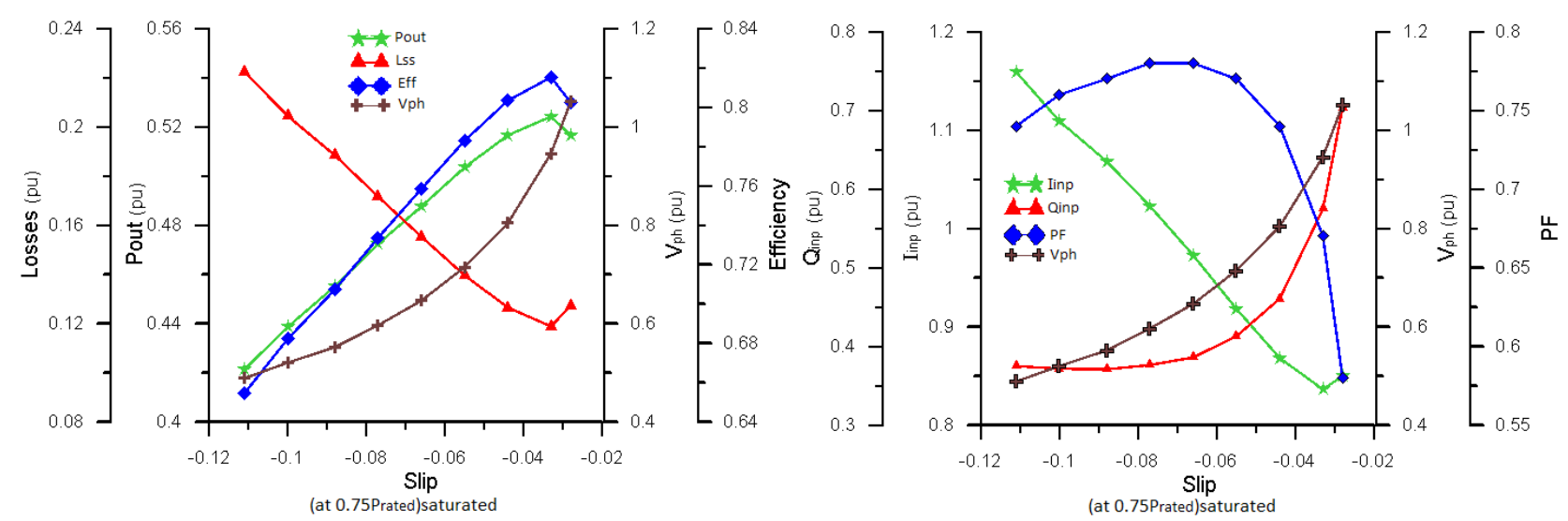

Figure 14. Experimental performance curves for constant driving power ( 0.75 times the rated input mechanical power). 

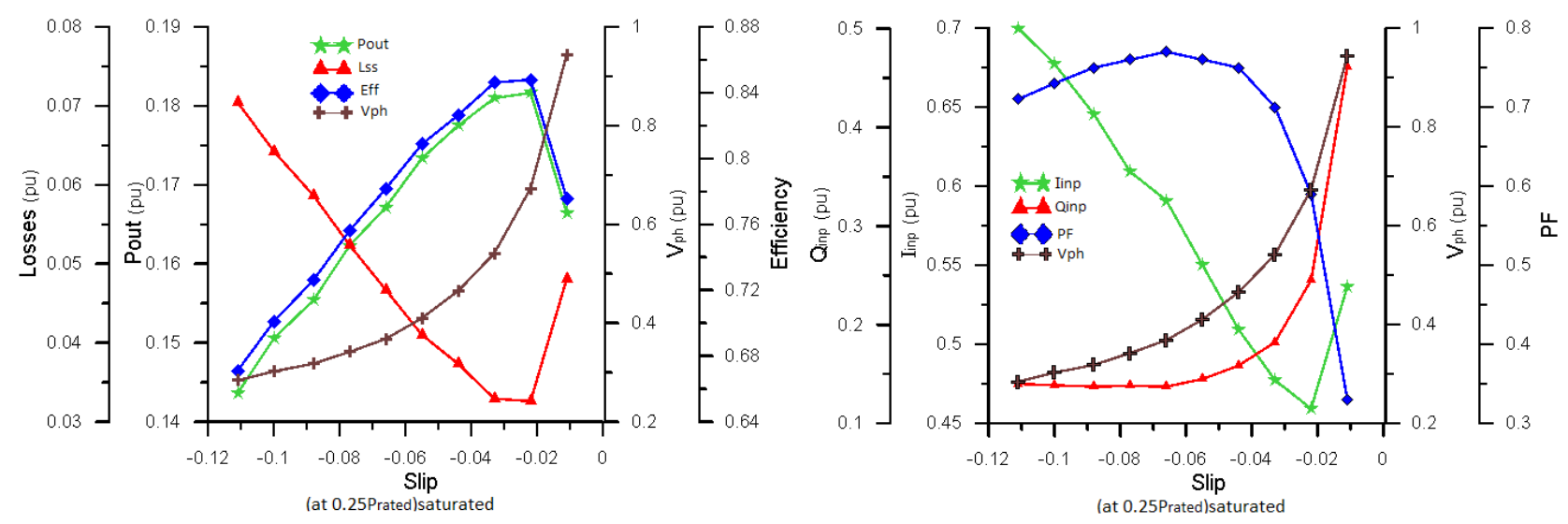

Figure 15. Experimental performance curves for constant driving power ( 0.25 times the rated input mechanical power).

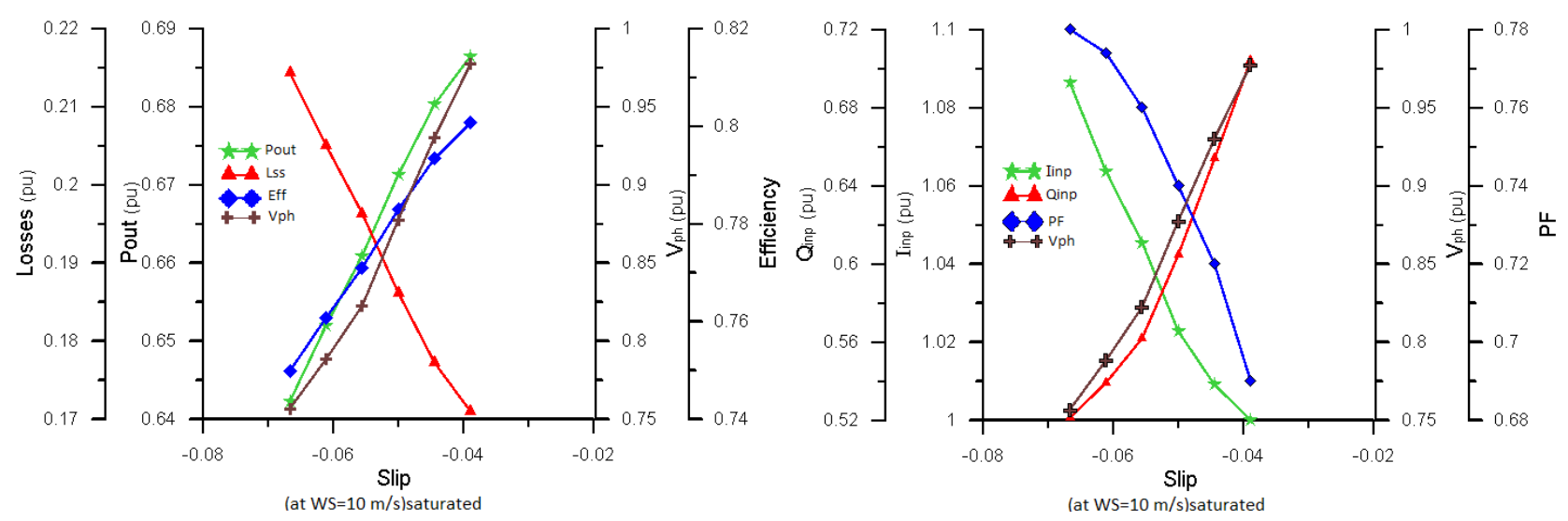

Figure 16. Experimental performance curves for constant wind speed $(10 \mathrm{~m} / \mathrm{s})$.
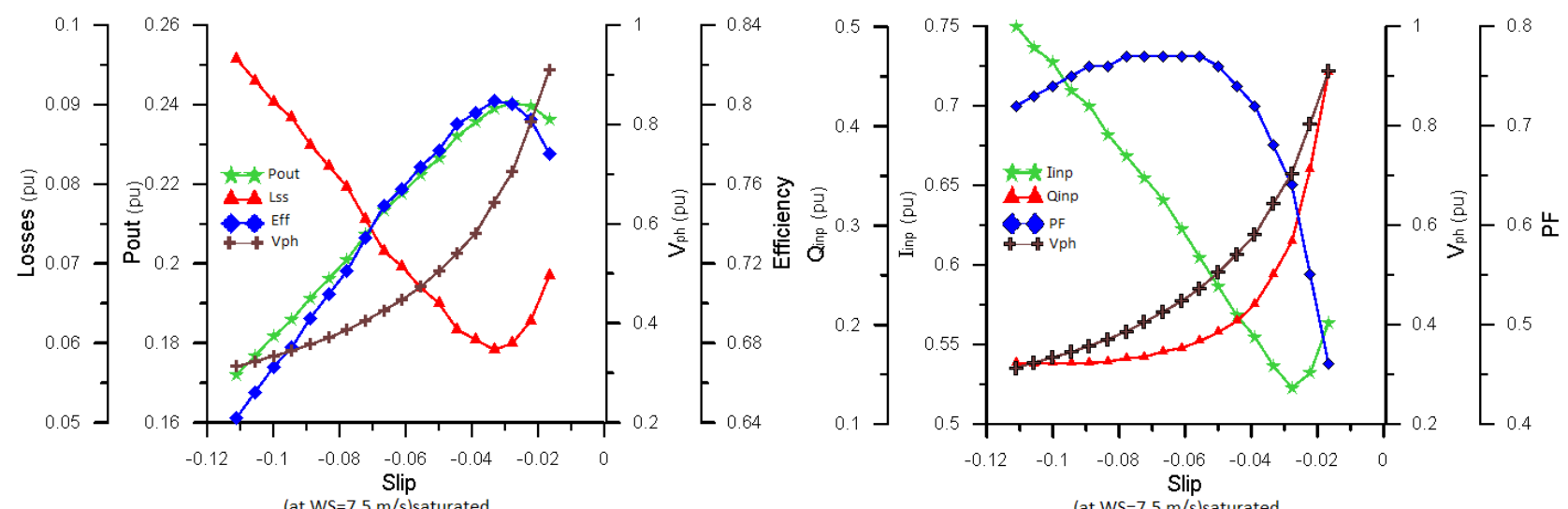

Figure 17. Experimental performance curves for constant wind speed $(7.5 \mathrm{~m} / \mathrm{s})$. 
The differences are due to measurement errors and other reasons such as neglecting the effect of saturation upon the generator leakage reactance. It is worth to mention that it is difficult to reach the optimizing slips at full-load conditions as one of the constraints will be violated. This is demonstrated by the condition of the constant wind speed of $10 \mathrm{~m} / \mathrm{s}$ (Figure 16). At lighter conditions the optimizing slips will be feasible.

\section{Conclusions}

The analysis and results presented in this study show that optimum operation of the induction generator can be achieved at a specified driving condition by reducing the applied voltage on the generator terminals to shift the slip such that one of the generator performance indices is optimized. The optimization process is feasible at light load conditions, and in this case non of the voltage or the current constraints will be violated.The study presented closed form formulae for the optimizing slips for both constant torque and constant power driving conditions neglecting the electromagnetic nonlinearities. In this case, the formulae show that the optimizing slips do not depend on the generator loading level. To study the constant windspeed driving condition in addition to the constant torque and constant power conditions, and to investigate the effects of the electromagnetic nonlinearities encountered in the generator, computer algorithms have been developed. The results achieved using these algorithms proved that the optimizing slips depend on the generator driving conditions and the level of saturation. In general, the optimizing slips increase with the increase of the saturation level encountered at the high loading levels. Closed loop control techniques employing micro-controller have been suggested to optimize the generator performance. Two control algorithms have been presented to suit the case of a generator of known parameters and the case of a generator of undetermined parameters. The experimental results validated the theoretical calculations, and proved that it is possible to optimize the performance indices of the induction generator by just adjusting its terminal voltage.

\section{References}

1. Renewable Energy Systems: Design and Analysis with Induction Generators. Date accessed: 11.05.2004. https:// books.google.co.in/books/about/Renewable_Energy_ Systems.html?id=FRG-w3LVTowC\&redir_esc=y.
2. Induction Generator for wind Power Generator. Date accessed: 2007. http://www.alternative-energy-tutorials. com/wind-energy/induction-generator.html.

3. Variable Speed Generators. Date accessed: 2016. https:// www.abebooks.com/9781498723572/Variable-SpeedGenerators-Second-Edition-1498723578/plp.

4. Ruben P. A Cage Induction Generator Using Back to Back PWM Converters for Variable Speed Grid Connected Wind Energy System. Annual Conference of the IEEE Industrial Electronics Society; 2001, 2. p. 1376-81. PMCid: PMC1301414.

5. Primary Frequency Control Participation Provided by Doubly Fed Induction Wind Generators. Date accessed: 22/08/2005. http://citeseerx.ist.psu.edu/viewdoc/download ?doi=10.1.1.552.2509\&rep=rep1\&type=pdf.

6. Shees MM, Bakhsh FH, Asghar J, Abdel-halim MA. Power factor improvement of combined input voltage and slip power control of low power wound rotor induction generator, International Journal of Engineering Research and Applications. 2011; 1(3):963-68.

7. Abdel-halim MA, Mahfouz AA, Almarshoud AF. Enhancing the performance of wind-energy-driven double-fed induction generators, Journal of Engineering and Computer Sciences. 2014; 7(1):23-41. https://doi. org/10.12816/0009556.

8. Abdel-halim MA, Mahfouz AA, Almarshoud AF. Enhancing the performance of a stator and rotor combined-controlled wind driven induction generator, Journal of King AbdulAziz University- Engineering Sciences. 2015; 26(1):3-23.

9. Babu B, Mohanty KB. DSP based stator flux oriented control of doubly-fed induction generator for wind power generation system, IEEE Students' Conference on Electrical, Electronics and Computer Science; 2012. p. 1-6.

10. Boumassata A, Kerdoun D, Cherfia N, Bennecib N. Performance of wind energy conversion systems using a cycloconverter to control a doubly fed induction generator, Energy Procedia. 2013; 42:143-52. https://doi. org/10.1016/j.egypro.2013.11.014.

11. Power Electronics and Drives. Date accessed: 20/05/2016. https://electronicsforu.com/resources/power-electronicsand-drives.

12. Jian JW, Schmitz NL, Novotry DW. Characteristic induction motor slip values for variable voltage part load performance optimization, IEEE Transactions on Power Apparatus and Systems. 1983; 102(1):38-46. https://doi.org/10.1109/ TPAS.1983.317995.

13. Abdel-halim MA, Almarshoud AF. Optimization of the performance of a grid-connected induction generator, Journal of King Abdul-Aziz University- Engineering Sciences. 2014; 25(1):33-51. 
14. Programming and customizing the PIC microcontroller. Date accessed: 22/05/2007. https://www.amazon. com/Programming-Customizing-PIC-MicrocontrollerElectronics-ebook/dp/B000SEHJMU.

15. Electric Machinery. Date accessed: 2003. https://www. worldcat.org/title/electric-machinery/oclc/49726399.

16. Ackermann T, S“oder L. An overview of wind energystatus, Renewable and Sustainable Energy Reviews. 2002; 6(1-2):67-127. https://doi.org/10.1016/S13640321(02)00008-4.

17. Bossanyi E. The design of closed loop controllers for wind turbines, Wind Energy. 2000; 3(3):149-63. https://doi. org/10.1002/we.34.

18. Leithead WE, Connor B. Control of variable speed wind turbines: Design task, International Journal of Control. 2000; 73(13):1189-212. https://doi. org/10.1080/002071700417830.

\section{Appendix A: Induction generator performance optimizing slips}

\section{(a) Constant Driving Torque}

$T=I_{2}^{2} \frac{R_{2}}{s}$ p.u

Thus, $I_{2}=\sqrt{\frac{T s}{R_{2}}}$

\section{i. Minimum output current:}

$$
\begin{aligned}
& \bar{E}=-I_{2}\left(\frac{R_{2}}{s}+j X_{2}\right) \\
& \left.\bar{I}_{e}=-I_{2}\left(\frac{R_{2}}{s}+j X_{2}\right)\right)\left(\frac{1}{R_{c}}-j \frac{1}{X_{M}}\right)=-I_{2}\left(\frac{R_{2}}{s R_{c}}+j \frac{X_{2}}{X_{M}}\right)+j I_{2}\left(\frac{R_{2}}{s R_{M}}-j \frac{X_{2}}{R_{c}}\right) \\
& \bar{I}_{1}=\bar{I}_{2}-\bar{I}_{e} \\
& =\sqrt{\frac{T s}{R_{2}}}\left[1+\frac{R_{2}}{s R_{c}}+\frac{X_{2}}{X_{M}}\right]+j \sqrt{\frac{T s}{R_{2}}}\left[\left(\frac{X_{2}}{R_{c}}-\frac{R_{2}}{s X_{M}}\right)\right] \\
& I_{1}^{2}=\frac{T s}{R_{2}}+\frac{T R_{2}}{s R_{c}^{2}}+\frac{2 T}{R_{c}}+\frac{T R_{2}}{s X_{M}^{2}}+\frac{T X_{2}^{2} s}{R_{2} R_{c}^{2}}+\frac{T X_{2}^{2} s}{R_{2} X_{M}^{2}}+\frac{2 T X_{2} s}{R_{2} X_{M}} \\
& \frac{d I}{d s}=0 \\
& S= \pm \sqrt{\frac{R_{2}^{2}\left(R_{c}^{2}+X_{M}^{2}\right)}{R_{c}^{2}\left(X_{M}+X_{2}\right)^{2}+X_{M}^{2} X_{2}^{2}}}
\end{aligned}
$$

$$
s_{I} \cong \pm \frac{R_{2}}{\left(X_{M}+X_{2}\right)}
$$

\section{ii. Minimum Losses:}

$$
\begin{aligned}
& P_{l}= I_{2}^{2} R_{2}+E^{2} / R_{c}+I_{1}^{2} R_{1} \\
&= T s+\frac{T R_{2}}{s R_{c}}+\frac{T X_{2}^{2} s}{R_{2} R_{c}}+\frac{T R_{1}}{R_{2}} s+\frac{T R_{1} R_{2}}{s R_{c}^{2}}+\frac{2 T R_{1}}{R_{c}} \\
& \quad+\frac{T R_{1} R_{2}}{s X_{M}^{2}}+\frac{T X_{2}^{2} R_{1} s}{R_{2} R_{c}^{2}}-\frac{2 T X_{2} R_{1}}{R_{c} X_{M}} \\
& \frac{d P_{l}}{d s}=0 \\
& s_{L}=\frac{R_{2}}{X_{M}}\left[\frac{\left(R_{c} X_{M}^{2}+R_{1} X_{M}^{2}+R_{1} R_{c}^{2}\right)^{1 / 2}}{\left(R_{2} R_{c}^{2}+X_{2}^{2} R_{c}+R_{1} R_{c}^{2}+2 R_{1} R_{2} R_{c}+X_{2}^{2} R_{1}\right)^{1 / 2}}\right] \\
& S \pm \frac{R_{2}}{\left[R_{c}\left(R_{1}+R_{2}\right)\right]^{1 / 2}}
\end{aligned}
$$

\section{iii. Minimum Input Reactive Power:}

$$
\begin{gathered}
Q=I_{2}^{2} X_{2}+E^{2} / X_{M}+I_{1}^{2} X_{1} \\
=\frac{T X_{2}}{R_{2}} s+\frac{T R_{2}}{s X_{M}}+\frac{T X_{2}^{2} s}{R_{2} X_{M}}+\frac{T X_{1}}{R_{2}} s+\frac{T X_{1} R_{2}}{s R_{c}^{2}}+\frac{2 T X_{1}}{R_{c}} \\
\quad+\frac{T X_{1} R_{2}}{s X_{M}^{2}}+\frac{T X_{2}^{2} X_{1} s}{R_{2} R_{c}^{2}}-\frac{2 T X_{2} X_{1}}{R_{c} X_{M}} \\
\frac{d Q}{d s}=0 \quad \\
S=\left[\frac{R_{2}^{2}\left(X_{M} R_{c}^{2}+X_{1} X_{M}^{2}+X_{1} R_{c}^{2}\right)}{X_{M}\left(X_{2} X_{M} R_{c}^{2}+X_{2}^{2} R_{c}^{2}+X_{1} X_{M} R_{c}^{2}+X_{1} X_{2}^{2} X_{M}\right)}\right]^{1 / 2} \\
s_{Q} \pm \frac{R_{2}}{\left[X_{M}\left(X_{1}+X_{2}\right)\right]^{1 / 2}}
\end{gathered}
$$

iv. Maximum Output Power:

$$
\begin{aligned}
P_{e}= & P_{m} \\
=- & -\frac{T R_{l}}{s R_{c}}-\frac{T X_{2}^{2} s}{R_{2} R_{c}}-\frac{T R_{1}}{R_{2}} s-\frac{T R_{1} R_{2}}{s R_{c}^{2}}-\frac{2 T R_{1}}{R_{c}} \\
& \quad-\frac{T R_{1} R_{2}}{s X_{M}^{2}}-\frac{T X_{2}^{2} R_{1} s}{R_{2} R_{c}^{2}}+\frac{2 T X_{2} R_{1}}{R_{c} X_{M}} \\
\frac{d P_{e}}{d s}=0 &
\end{aligned}
$$


$S=\frac{R_{2}\left(R_{c} X_{M}^{2}+R_{1} X_{M}^{2}+R_{1} R_{c}^{2}\right)^{1 / 2}}{X_{M}\left(R_{c} X_{2}^{2}+R_{1} R_{c}^{2}+R_{1} X_{2}^{2}\right)^{1 / 2}}$

$S_{e} \pm \frac{R_{2}}{\sqrt{R_{1} R_{c}}}$

v. Maximum Efficiency:

$\eta=\frac{P_{e}}{P_{m}}$

$\frac{d \eta}{d s}=0$

$$
P_{m} \frac{d P_{e}}{d s}-P_{e} \frac{d P_{m}}{d s}=0
$$

$$
\begin{aligned}
\left(\frac{R_{2}}{R_{c}}\right. & \left.+\frac{R_{1} R_{2}}{R_{c}^{2}}+\frac{R_{1} R_{2}}{X_{M}^{2}}\right)-\left(\frac{2 R_{2}}{R_{c}}+\frac{2 R_{1} R_{2}}{R_{c}^{2}}+\frac{2 R_{1} R_{2}}{X_{M}^{2}}\right) s \\
& -\left(\frac{X_{2}^{2}}{R_{2} R_{c}}+\frac{R_{1}}{R_{2}}+\frac{X_{2}^{2} R_{1}}{R_{2} R_{c}^{2}}+1+\frac{2 R_{1}}{R_{c}}-\frac{2 X_{2} R_{1}}{R_{c} X_{M}}\right) s^{2}=0
\end{aligned}
$$

Approximately,

$$
\begin{aligned}
\left(1+\frac{R_{1}}{R_{2}}\right) s^{2} & +\frac{2 R_{2}}{R_{c}} s-\frac{R_{2}}{R_{c}}=0 \\
& \cong \cong \pm \frac{R_{2}}{\sqrt{\left(R_{1}+R_{2}\right) R_{c}}}-\frac{R_{2}^{2}}{\sqrt{\left(R_{1}+R_{2}\right) R_{c}}}
\end{aligned}
$$

$2^{\text {nd }}$ approximation,

$$
s_{\eta} \cong \pm \frac{R_{2}}{\sqrt{\left(R_{1}+R_{2}\right) R_{c}}}
$$

\section{vi. Maximum Power factor:}

$\tan \varphi=\frac{Q}{P_{e}}$

Maximum power factor occurs when $\varphi$ is minimum, which means $\tan \varphi$ is minimum. Then,

$$
\begin{gathered}
P_{e} \frac{d Q}{d s}-Q \frac{d P_{e}}{d s}=0 \\
\left(X R_{c}^{2} X_{M}+2 X_{2} X_{M} R_{1} R_{c}\right) s^{2}+\left(2 X R_{2} X_{M} R_{c}-2 R_{1} R_{2} R_{c}^{2}\right) s \\
-\left(R_{2}^{2} R_{c}^{2}+2 R_{1} R_{2}^{2} R_{c}-2 X_{1} X_{M} R_{2}^{2}\right)=0
\end{gathered}
$$

Let $X=X_{1}+X_{2}$, thus, approximately

$$
X R_{c} X_{M} s^{2}+\left(2 X R_{2} X_{M}-2 R_{1} R_{2} R_{c}\right) s-R_{2}^{2} R_{c}=0
$$

$$
s_{p f}=\frac{-X_{2} R_{2} X_{M} \pm \sqrt{4\left(X R_{2} X_{M}-R_{1} R_{2} R_{c}\right)^{2}+4 X R_{2}^{2} X_{M} R_{c}^{2}}}{2 X X_{M} R_{c}}
$$

\section{b) Constant Input Power}

Maximum efficiency will be obtained at the same slip which gives maximum efficiency for constant driving torque. As $\mathrm{P}_{\mathrm{m}}$ is constant then maximum output power and minimum losses will be obtained at the same slip of maximum efficiency. Maximum power factor will be obtained at the same slip which gives maximum power factor at constant driving torque. Consequently,

$$
\begin{gathered}
s_{L}^{\prime}=s_{e}^{\prime}=s_{\eta}^{\prime} \cong \pm \frac{R_{2}}{\sqrt{\left(R_{1}+R_{2}\right) R_{c}}} \\
s_{p f}^{\prime}=s_{p f}=\frac{-X_{2} R_{2} X_{M} \pm \sqrt{4\left(X R_{2} X_{M}-R_{1} R_{2} R_{c}\right)^{2}+4 X R_{2}^{2} X_{M} R_{c}^{2}}}{2 X X_{M} R_{c}}
\end{gathered}
$$

The slips for minimum current and reactive powers are derived hereafter.

\section{i. Minimum output current:}

$$
\begin{gathered}
I_{1}^{2}=\frac{P_{m} s}{(1-s) R_{2}}+\frac{P_{m} R_{2}}{(1-s) s R_{c}^{2}}+\frac{2 P_{m}}{(1-s) R_{c}}+\frac{P_{m} R_{2}}{(1-s) s X_{M}^{2}} \\
+\frac{P_{m} X_{2}^{2} s}{(1-s) R_{2} R_{c}^{2}}+\frac{P_{m} X_{2}^{2} s}{(1-s) R_{2} X_{M}^{2}}+\frac{2 P_{m} X_{2} s}{(1-s) R_{2} X_{M}} \\
s_{I}^{\prime} \cong \frac{R_{2}}{X_{M}^{1 / 2}\left(X_{M}+2 X_{2}\right)^{1 / 2}}
\end{gathered}
$$

ii. Minimum input reactive power:

$$
\begin{gathered}
\mathrm{Q}=\frac{P_{m} X_{2}}{(1-s) R_{2}} s+\frac{P_{m} R_{2}}{s(1-s) X_{M}}+\frac{P_{m} X_{2}^{2} s}{(1-s) R_{2} X_{M}} \\
+\frac{P_{m} X_{1}}{(1-s) R_{2}} s+\frac{P_{m} X_{1} R_{2}}{s(1-s) R_{c}^{2}}+\frac{2 P_{m} X_{1}}{(1-s) R_{c}}+\frac{P_{m} X_{1} R_{2}}{s(1-s) X_{M}^{2}} \\
+\frac{P_{m} X_{2}^{2} X_{1} s}{(1-s) R_{2} R_{c}^{2}}-\frac{2 P_{m} X_{2} X_{1}}{(1-s) R_{c} X_{M}} \\
s_{Q} \cong \pm \frac{R_{2}}{\left[X_{M}\left(X_{1}+X_{2}\right)\right]^{1 / 2}}
\end{gathered}
$$


Optimization Constraint Voltage constraints:

$\bar{V}_{1}=\bar{E}+\left[\sqrt{\frac{T s}{R_{2}}}\left(1+\frac{R_{2}}{s R_{c}}+\frac{X_{2}}{X_{M}}\right)+j \sqrt{\frac{T s}{R_{2}}}\left(\frac{X_{2}}{R_{c}}-\frac{R_{2}}{X_{2}}\right)\right]\left[R_{1}+j X_{1}\right]$

$\bar{V}_{1}=-\sqrt{\frac{T s}{R_{2}}}\left(\frac{R_{2}}{s}+j X_{2}\right)+\sqrt{\frac{T s}{R_{2}}}\left(R_{1}+\frac{R_{1} R_{2}}{s R_{c}}+\frac{R_{1} X_{2}}{X_{M}}+\frac{R_{2} X_{1}}{s X_{M}}-\frac{X_{1} X_{2}}{R_{c}}\right)$ $-j \sqrt{\frac{T s}{R_{2}}}\left(X_{1}+\frac{X_{1} R_{2}}{s R_{c}}+\frac{X_{1} X_{2}}{X_{M}}+\frac{R_{1} X_{2}}{R_{c}}-\frac{R_{2} R_{1}}{s X_{M}}\right)$

$V_{1}^{2} \cong \frac{T s}{R_{2}}\left(-\frac{R_{2}}{s}+R_{1}\right)^{2}+\frac{T s}{R_{2}}\left(X_{2}+X_{1}\right)^{2}$

$V_{1} \ll V_{r}$

$\left(\frac{T R_{1}^{2}}{R_{2}}+\frac{T X_{1}^{2}}{R_{2}}+\frac{2 T X_{2} X_{1}}{R_{2}}+\frac{T X_{2}^{2}}{R_{2}}\right) s^{2}-\left(V_{r}^{2}+2 T R_{1}\right) s+T R_{2}=0$

Solve for $s$ to get $s_{1}^{v}$ and $s_{2}^{v}$, and safe operation is between these two slips.

\section{Current constraint:}

$$
\begin{aligned}
I_{1}^{2}=\frac{T s}{R_{2}} & +\frac{T X_{2}^{2} s}{R_{2} R_{c}^{2}}+\frac{T X_{2}^{2} s}{R_{2} X_{M}^{2}}+\frac{2 T X_{2} s}{R_{2} X_{M}}+\frac{2 T}{R_{c}} \\
& +\frac{T R_{2}}{s R_{c}^{2}}+\frac{T R_{2}}{s X_{M}{ }^{2}}
\end{aligned}
$$

$I_{1} \ll I_{f l}$

$$
\begin{aligned}
\left(\frac{T}{R_{2}}+\right. & \left.\frac{T X_{2}^{2}}{R_{2} R_{c}^{2}}+\frac{T X_{2}^{2}}{R_{2} X_{M}^{2}}+\frac{2 T X_{2}}{R_{2} X_{M}}\right) s^{2} \\
& -\left(I_{f l}^{2}+\frac{2 T}{R_{c}}\right) s+\left(\frac{T R_{2}}{R_{c}^{2}}+\frac{T R_{2}}{X_{M}^{2}}\right)=0
\end{aligned}
$$

Solve for $s$ to get $s_{1}^{i}$ and $s_{2}^{i}$, and safe operation is between these two slips.

\section{Appendix B: Induction Machines Data and Parameters}

\section{Ratings and Parameters of the Induction Machine:}

The laboratory cage induction machine has the following particulars:

$1448 \mathrm{VA}, 380 \mathrm{~V}, 60 \mathrm{~Hz}, 1870 \mathrm{rpm}$, 3-phase induction machine has the following parameters in p.u:

$$
\mathrm{R}_{1}=0.082, \mathrm{R}_{2}=0.0599, \mathrm{X}_{1}=\mathrm{X}_{2}=0.0893, \mathrm{X}_{\mathrm{m}}=1.98 \text {, }
$$
$\mathrm{R}_{\mathrm{c}}=28.44$

$\mathrm{X}_{\mathrm{m}}$ (p.u) $=0.4773+8.749 \mathrm{E}-16.53 \mathrm{E}^{2}+13.37$ $\mathrm{E}^{3}-0.091 \mathrm{E}^{4}$

$R_{c}$ (p.u) $=1080 \mathrm{e}^{-(0.4203 / \mathrm{E}+3.26 \mathrm{E})}$

where $\mathrm{E}$ is the induced voltage in p.u 